\title{
Reservation Wages of First and Second Generation Migrants*
}

\author{
Amelie F. Constant \\ DIW DC, IZA, \\ George Washington University
}

\author{
Annabelle Krause \\ IZA
}
Ulf Rinne
IZA

\author{
Klaus F. Zimmermann \\ IZA, DIW Berlin, \\ University of Bonn
}

April 14, 2010

\begin{abstract}
This paper analyzes the reservation wages of first and second generation migrants in Germany. Based on recently collected and rich survey data of a representative sample of entrants into unemployment, we empirically test and confirm the hypothesis that reservation wages increase from first to second generation migrants, other things equal. Two extensions of the basic model of job search provide theoretical justifications for this hypothesis. In both cases, changing frames of reference are identified as a channel through which the phenomenon of increasing reservation wages may arise.

Our empirical results show an unconditional reservation wage gap of 4.3 percent between first and second generation migrants, which increases to about 5.1 percent once differences in characteristics are taken into account. Moreover, we present evidence that changing frames of reference explain at least part of this gap: if we additionally control for reference groups via the ethnosizer, the gap decreases to 3.7 percent and becomes statistically insignificant. A decomposition analysis furthermore suggests that a substantial part of the unconditional gap is driven by higher self-evaluated returns to characteristics of second generation migrants, especially with respect to education.
\end{abstract}

Keywords: $\quad$ Migration; Ethnic Identity; Ethnosizer; Germany; Unemployment; Job Search; Reservation Wages

JEL Classification: $\quad$ F22; J15; J61; J64

*We would like to thank Simone Schüller for helpful discussions and comments on earlier drafts of this paper. Financial support from the German Research Foundation (Deutsche Forschungsgemeinschaft, DFG) for the project on "Ethnic Diversity and Labor Market Success" in the DFG-Priority Program "Flexibility in Heterogeneous Labor Markets" (Flexibilisierungspotenziale bei heterogenen Arbeitsmärkten) is gratefully acknowledged. The IAB (Nuremberg) kindly gave us permission to use the data. The usual disclaimer applies. 


\section{Introduction}

In many countries, migrants show higher unemployment rates, lower employment rates and lower earnings when compared to natives (see, e.g., Kahanec and Zaiceva, 2009). The literature which aims at explaining the migrant-native differences in economic outcomes is large, but most of the studies focus on first generation migrants, i.e., migrants who have themselves moved from one country to another. Second generation migrants, i.e., the offspring of first generation migrants, have received less attention. ${ }^{1}$ However, this group of migrants is more and more a concern, both from an academic and policy perspective. In the course of the past century, many countries have accumulated sizeable stocks of migrants and their descendants. Although one would expect migrant-native differences in economic outcomes to decrease from one generation to the next, this is generally not the case (see Algan et al., 2010, for evidence on France, Germany and the UK).

Germany can be considered as an interesting example in this regard. It has received relatively large migration inflows over a long period, and therefore sizeable stocks of both first and second generation migrants are present. In 2007, almost 19 percent of the German population (or 15.4 million persons) had a migration background. Fewer than half of those are actually foreign citizens. Among children aged 5 and below, the share is even higher: around one third is descended from a family with a migration background. Turks are by far the largest group of individuals with a migration background (about 2.5 million in 2007), followed by Poles, Russians and Italians (Rühl, 2009).

In addition, native-migrant gaps in economic outcomes are relatively persistent over the two generations of migrants in Germany. Algan et al. (2010) provide crosscountry evidence on the performance of first and second generation migrants in terms of education, earnings and employment. Results for Germany indicate lower educational outcomes of first generation immigrants when compared to natives, and in particular for those from traditional guest worker countries. The educational attainment however improves substantially for second generation immigrants, yet outcomes are still below those of natives. With respect to earnings, the authors conclude that wage assimilation from one generation to the next is weak, and that there remains a substantial wage differential for all immigrant groups even in the second generation. Additionally, it is found that native-migrant employment gaps in Germany are relatively large, in particular for Turks and Central and Eastern Europeans, and that, at least for men, those gaps do not appear to decrease from one generation to the next.

\footnotetext{
${ }^{1}$ Exceptions for Germany comparing the economic outcomes of immigrants, immigrants' children and natives include Gang and Zimmermann (2000), Riphahn (2003) and Uhlendorff and Zimmermann (2006).
} 
The lack of intergenerational improvement is puzzling. However, there are a number of potential explanations discussed in the literature. Firstly, second generation migrants may be discriminated against in the labor market. One would expect ethnic discrimination to be primarily a concern for first generation migrants, but evidence from various European countries indicates that also second generation migrants are affected (see, e.g., Jonsson, 2007, and other studies in the same volume). Moreover, as far as second generation migrants do not have the citizenship of the host country, they may also face institutional discrimination (Kogan, 2007; Phalet, 2007). Secondly, the endowment of second generation migrants in terms of ethnic and human capital may be another explanation for the lack of intergenerational improvement. The quality of the ethnic environment of first generation migrants, i.e., ethnic capital (Borjas, 1992), influences the skills and labor market outcomes of their offspring. Card et al. (1998) show that the higher the parents' education, the higher are the children's education, earnings, and the probability to marry outside their father's ethnic group. Kalter and Granato (2007) conclude that missing relevant human capital is still an important explanation for the lack of intergenerational improvement in Germany. Thirdly, there are explanations for the persistence of native-migrant gaps in economic outcomes across migrant generations which are based on ethnic identity. For example, the concept of 'downward assimilation' describes the assimilation of the second generation with the native underclass, which might lead to a permanent marginalization. Such developments are documented in the United States (Portes and Zhou, 1993) and in Europe (Silberman and Fournier, 2007; Heath et al., 2008). Two other processes are discussed in the literature: 'taste for isolation' and 'oppositional identities' (Blackaby et al., 2005). Both either result from discrimination or are made by choice, i.e., certain immigrant groups may actually like to isolate themselves from the receiving society or develop resentments against the dominant host culture.

Whereas those approaches focus on the lack of intergenerational improvement in terms of economic outcomes, this paper takes a slightly different perspective. It concentrates on one important underlying mechanism in determining economic outcomes: the process of job search. Since employment biographies become more unstable and more fragmented, and labor markets in general more flexible, the importance of this process increases. But there may be crucial differences in job search behavior between first and second generation migrants. For instance, Heath and Li (2008) argue that the lack of intergenerational improvement in the United Kingdom may be explained by differences in the willingness to accept low paid jobs or to work in the enclave economy. The failure to catch up across generations could result from lower reservation wages of first generation migrants when compared to their offspring. Changing frames of reference from one migrant generation to the next are identified as a potential channel through which this phenomenon may arise. 
Whereas the comparative reference group of first generation migrants may be their families, co-ethnics and peers in the country of origin, second generation migrants may expect to be treated like peers from the host country. Similarly, Stark and Taylor (1991) develop the hypothesis that international migrants (i.e., first generation migrants) keep their reference group in their country of origin in order to improve their relative position within their original reference group. This positive effect of migration might be outweighed by changing the reference group to one in the host society. The more different the home and host societies are, the less likely is thus reference group substitution. ${ }^{2}$

This paper empirically tests and confirms the hypothesis that reservation wages of second generation migrants exceed those of first generation migrants, other things equal. Two extensions of the basic model of job search provide theoretical justifications for the hypothesis: $a$ ) an unknown wage offer distribution, and $b$ ) reference standards. In both cases, changing frames of reference are identified as a channel through which the phenomenon of increasing reservation wages from one migrant generation to the next may arise. Our empirical analysis uses data on recent entrants into unemployment in Germany at a very early stage of the unemployment spell. ${ }^{3}$ Potentially different reference groups between the two migrant generations are approximated by measures of ethnic identity. Our results show an unconditional reservation wage gap of 4.3 percent between first and second generation migrants, which increases to about 5.1 percent once differences in characteristics are taken into account. Moreover, we present evidence that changing frames of reference explain at least part of this gap: if we additionally control for reference groups via the ethnosizer, the gap decreases to 3.7 percent and becomes statistically insignificant. A decomposition analysis furthermore suggests that a substantial part of the unconditional gap is driven by higher self-evaluated returns to characteristics of second generation migrants, especially with respect to education.

The remainder of this paper is organized as follows. After discussing theoretical considerations in Section 2, we give an overview about our data in Section 3. Section 4 presents our results, a sensitivity analysis is performed in Section 5 and, finally, Section 6 concludes.

\footnotetext{
${ }^{2}$ The assumption about reference group substitution is part of the "relative deprivation hypothesis." According to this hypothesis, relatively more deprived households in the home country are more likely to send migrants to foreign labor markets given that there is an expected income gain (Stark and Taylor, 1991).

${ }^{3}$ Reservation wages of migrants in Germany were also studied in Constant and Zimmermann (2005). However, this analysis does not distinguish between first and second generation migrants.
} 


\section{Theoretical Considerations}

This section provides theoretical arguments for our hypothesis that reservation wages increase from first to second generation migrants. We start by briefly reviewing the basic model of job search and extend this framework in two ways: $a$ ) we relax the assumption of a known wage offer distribution, and $b$ ) we directly incorporate a reference standard into the model. Both extensions provide theoretical justifications that changing frames of reference are a channel through which the phenomenon of increasing reservation wages from one migrant generation to the next may arise.

\subsection{The Basic Model of Job Search}

The starting point of our analysis is the basic (or standard) model of job search (McCall, 1970; Mortensen, 1970). ${ }^{4}$ In this model the reservation wage represents the crucial wage above which an individual is willing to accept job offers. It is assumed that unemployed individuals seek to maximize the expected present value of future income streams over an infinite horizon. In a given period, a job offer with wage $w$ is received with probability $\lambda$, where $w$ is an exogenously determined random variable distributed according to the wage offer distribution $H(w)$. Importantly, this distribution is assumed to be known to the job seeker.

The basic setup furthermore assumes that $a$ ) individuals are risk neutral, $b$ ) the discount rate is equal to $d, c$ ) jobs are separated exogenously with probability $q$ per period, $d$ ) search is costless, $e$ ) non-labor income equals $b$ per period, and $f$ ) there is no on-the-job search. It can then be shown that the (unique) reservation wage $\xi$ is determined by the following equation:

$$
\xi=b+\frac{\lambda}{d+q} \int_{\xi}^{\infty}(w-\xi) \mathrm{d} H(w) .
$$

Therefore, the individual's reservation wage $\xi$ depends on the income stream during job search $b$, the job arrival rate $\lambda$, the discount rate $r$, and the job separation rate $q$. Employing the implicit function theorem, comparative static analysis reveals:

$$
\frac{\partial \xi}{\partial b}>0 ; \frac{\partial \xi}{\partial \lambda}>0 ; \frac{\partial \xi}{\partial d}<0 ; \frac{\partial \xi}{\partial q}<0
$$

Hence, according to the basic model the reservation wage $\xi$ depends positively on the income stream during job search $b$ and the job arrival rate $\lambda$, while it decreases with the discount rate $d$ and the job separation rate $q$.

There are several extensions to the basic model of job search, addressing and

\footnotetext{
${ }^{4}$ See also Chapter 3 of Cahuc and Zylberberg (2004).
} 
relaxing assumptions which may be an oversimplification. In what follows, we incorporate two extensions to the basic model: $a$ ) an unknown wage offer distribution, and $b$ ) reference standards.

\subsection{Unknown Wage Offer Distribution}

The assumption of a known wage offer distribution $H(w)$ is sometimes referred to as one of the most heroic assumption of job search models (Franz, 1980). But relaxing this assumption has important implications: if this distribution is unknown, the reservation wage becomes a function of the job seeker's beliefs.

Burdett and Vishwanath (1988) formulate a model which is based on the assumption that workers do not have precise knowledge of the distribution of the prevailing wages. ${ }^{5}$ The study is frequently cited for showing that in such situation, where learning takes place during job search, the individual reservation wage declines as a consequence of the selection process during the ongoing unemployment spell. However, the authors also address the situation at the very beginning of the unemployment spell. At the start of search, job seekers form beliefs about the unknown distribution $H(w)$, summarizing the knowledge which has been accumulated through various sources of information (e.g., newspapers, wage statistics, wages of friends, relatives, or colleagues). In this setup, the reservation wage is therefore a function of the workers' beliefs-at the beginning of the respective unemployment spell based on external information, and subsequently modified after wage offers have been received.

How are initial beliefs about the wage offer distribution formed? We argue that reference groups play a crucial role in this regard, and that these reference groups shift from one migrant generation to the next (Heath and Li, 2008). More precisely, our working hypothesis is that first generation migrants are still relatively strongly attached to their country of origin, and therefore sources of information which they use to form beliefs (i.e., their reference groups) come to a sizeable extent from abroad. In contrast, beliefs of second generation migrants are supposedly more strongly based on German experiences, as we expect reference groups to shift over migrant generations. Given that wage levels in migrants' home countries are below those of Germany, we thus expect reservation wages to increase from first to second generation migrants.

Subsequently, i.e., in the course of the unemployment spell, beliefs are modified after wage offers have been received. But one can find arguments that our working hypothesis is still applicable: social networks and personal contacts are a

\footnotetext{
${ }^{5}$ Other studies relaxing the assumption of search models that the wage (or price) offer distribution is known include Kohn and Shavell (1974), Rothschild (1974), Bikhchandani and Sharma (1996) and Dubra (2004).
} 
major source for information about job offers, and a substantial share of jobs are found through these channels (Granovetter, 1995; Franzen and Hangartner, 2006). Similarly, updating initial beliefs may also work through the process of peer updating, i.e., via wage offers which members of the individuals' network have received rather than the individuals themselves (Kriechel and Pfann, 2006). But if the composition of social networks, or peer groups, shifts from one migrant generation to the next accordingly (i.e., from stronger attachment to the country of origin towards a more German-oriented perspective), reservation wages of first generation migrants are also in the course of the unemployment spell lower than those of second generation migrants, other things equal.

\subsection{Reference Standards}

So far, reference standards are only indirectly included in the model by assuming that they play a crucial role in forming beliefs about the (unknown) wage offer distribution. A slightly different, albeit related extension directly incorporates a reference standard $r$ into this framework.

More specifically, we assume that the absolute wage $w$ as well as the relative wage $(w-r)$ contribute in a linear way to the utility of an employed individual. ${ }^{6}$ The discounted expected utility $V_{e}$ of an employed person can then be expressed as:

$$
V_{e}(w)=\frac{1}{1+d}\left((1-\theta) w+\theta(w-r)+(1-q) V_{e}(w)+q V_{u}\right),
$$

where the discount rate is equal to $d$, the parameter $\theta$ determines the extent to which comparisons play a role, jobs are separated exogenously with probability $q$ per period, and $V_{u}$ is the discounted expected utility of an unemployed person. Note that the discounted expected income of an unemployed individual does not change compared to the basic model of job search.

Utility maximization and rearranging terms ${ }^{7}$ yields the following expression for the reservation wage $\xi$ :

$$
\xi=b+\frac{\lambda}{d+q} \int_{\xi}^{\infty}(w-\xi) \mathrm{d} H(w)+\theta r .
$$

The reservation wage $\xi$ is increasing in the reference standard $r$ as well as in $\theta$, i.e., in the extent to which comparisons play a role. Changing frames of reference are thus a channel through which increasing reservation wages from one migrant generation to the next may arise, if the reference standard $r$ shifts accordingly across generations.

\footnotetext{
${ }^{6}$ See, e.g., Falk and Knell (2004) for a more general model of reference standards. They employ a similar specification into a more general framework of utility maximization.

${ }^{7}$ See Section A1 (Appendix) for a more detailed representation, including interim steps.
} 


\section{Data}

We test the hypothesis of increasing reservation wages from one migrant generation to the next using data from the IZA Evaluation Dataset (Caliendo et al., 2009). We concentrate on one of the two pillars of the data: a survey of almost 18,000 individuals who entered unemployment between June 2007 and May 2008. One of the many advantages of the data is that a sizeable sample of individuals were interviewed shortly after entering unemployment. Our analysis is based on the first wave of the survey, which takes place about 2 months after unemployment entry. The respondents were interviewed again one year later. ${ }^{8}$ But the main advantage of the data is clearly the large variety of topics which are addressed: questions cover many important individual characteristics which are rarely available for economic research but have been shown to influence economic outcomes. Examples include personality traits (Borghans et al., 2008), attitudes (Bonin et al., 2007), cognitive skills (Heckman et al., 2006), and ethnic identity (Constant and Zimmermann, 2009).

Importantly, the interviewees in our data report their reservation wages (details are given below). This feature of the data is obviously crucial for this study. Moreover, we have information about the individuals' ethnic identity, measured by the ethnosizer (Constant, Gataullina, and Zimmermann, 2009). One dimension of this multi-dimensional concept, ethnic self-identification, is available both for migrants and natives in our data (Constant, Kahanec, Rinne, and Zimmermann, 2009). As far as these measures can be viewed as approximations of frames of references, they allow us to test our working hypothesis with our data. Finally, the setup of the survey has explicitly taken into account the specific situation of migrants in Germany. Next to a detailed assessment of the individuals' migration background, the interviews were-dependent on the language skills of the interviewee-also available in Turkish and Russian. Those are the native languages of two major groups of immigrants in Germany. Altogether, 207 individuals were interviewed in those languages.

For our analysis, we select individuals between 18 and 55 years old when entering unemployment to avoid difficulties with accounting for the decision to (early-)retire, and we exclude individuals with missing information on important characteristics. Furthermore, we focus on individuals who are unemployed job seekers when the first interview takes place. Only those individuals are requested to state their reservation wages. Among those, we furthermore drop the top and bottom percentile of the reported net hourly reservation wages. After applying these criteria, our sample consists of 7,496 individuals, among those 1,129 with a migration background: we consider 773 individuals as first generation migrants and 356 persons as second generation migrants. First generation are individuals who are

\footnotetext{
${ }^{8}$ Another round of interviews has not started yet. It is scheduled three years after the relevant entry into unemployment.
} 
not German-born and have moved to Germany when they were at least four years old. Second generation migrants include $a$ ) individuals who are German-born, but do not have German citizenship or both parents are not German-born, and $b$ ) individuals who are not German-born, but have moved to Germany when they were at most three years old. Note that a foreign-born mother or father alone is not sufficient to be included in our definition of second generation migrants. We argue that such family background would entail already a rather strong attachment to the German culture. Furthermore, we include individuals in our definition of second generation migrants who have moved to Germany themselves, but who were very young then. Because they have gone through the entire (school and pre-school) education system in Germany, it is very likely that the societal integration process of those migrants is substantially different from individuals who have moved at later ages. ${ }^{9}$

Table 1 displays descriptive statistics of our sample by migration background. First and second generation migrants are on average younger than natives. The gender distribution is almost equal in all three subgroups. Roughly two thirds of first generation migrants are German citizens. This can be explained by the substantial inflow of ethnic Germans who immigrated from the former USSR and Central and Eastern European countries, in particular around 1990. Those individuals were usually granted German citizenship upon arrival. Moreover, the migrants in our sample have been in Germany for a relatively long time, and thus for many of them it became possible to obtain German citizenship. ${ }^{10}$ The share of German citizenship holders among the second generation is slightly lower (about 60 percent). The legal situation of naturalization in Germany has changed in 2000, when the German citizenship law was reformed. Before the reform, primarily the principle of descent (ius sanguis) and naturalization after at least 15 years of residence were the possibilities of obtaining German citizenship. After the reform also the law of soil (ius soli) is available for immigrant children born in Germany, and years of residence to apply for naturalization were reduced to eight (with exceptions such as three years for persons with a German spouse). ${ }^{11}$

One in three natives in our sample lives in East Germany, whereas only about 7 percent of first generation and 10 percent of second generation migrants do. The share of married individuals among first generation migrants is higher than among the other two groups. Regarding educational and vocational attainment, the share of first and second generation migrants without a formal degree is higher than that of natives. However, more first generation migrants have a general qualification

\footnotetext{
${ }^{9}$ See, e.g., Åslund et al. (2009) who emphasize the importance of the age at migration for the migrants' integration process.

${ }^{10}$ Years since migration are 16 years on average, see Table 2.

${ }^{11}$ For a more detailed description and analysis of the naturalization process in Germany, see Zimmermann, Constant, and Gataullina (2009).
} 
for university entrance as well as a university or technical college degree than natives. The latter rather have a secondary school degree of 10 years and completed an apprenticeship. Regarding previous employment, i.e., the employment before individuals entered unemployment and were interviewed, the average net hourly wage of natives is slightly higher than the previous wage of second generation migrants. The average previous wage of the second generation in turn exceeds that of the first generation. Natives had also longer lasting jobs than both migrant groups. But altogether, the three groups of recent entrants into unemployment had a relative strong attachment to the labor market in the past. This is also due to the design of our sample, as we only have information about people who had entered unemployment and registered with the Federal Employment Agency, importantly without being (registered as) unemployed in the preceding month. ${ }^{12}$

\footnotetext{
${ }^{12}$ Our sample was designed to consist of individuals who actually entered unemployment, thus coming from a different labor market status. We thus exclude for example long-term unemployed; and the vast majority of our sample was previously employed.
} 
Table 1: Descriptive Statistics (Selected Variables)

\begin{tabular}{|c|c|c|c|}
\hline & Natives & 1st gen. & 2nd gen. \\
\hline \multicolumn{4}{|l|}{ Sociodemographic characteristics } \\
\hline \multirow[t]{2}{*}{ Age (in years) } & 36.922 & 35.260 & 31.461 \\
\hline & $(10.231)$ & $(9.772)$ & (9.189) \\
\hline \multirow[t]{2}{*}{ Male } & 0.500 & 0.490 & 0.517 \\
\hline & $(0.500)$ & $(0.500)$ & $(0.500)$ \\
\hline \multirow[t]{2}{*}{ German citizenship } & 1.000 & 0.669 & 0.590 \\
\hline & $(0.000)$ & $(0.471)$ & $(0.493)$ \\
\hline \multirow[t]{2}{*}{ East Germany } & 0.344 & 0.074 & 0.101 \\
\hline & $(0.475)$ & $(0.262)$ & $(0.302)$ \\
\hline \multirow[t]{2}{*}{ Married } & 0.447 & 0.599 & 0.435 \\
\hline & $(0.497)$ & $(0.490)$ & $(0.497)$ \\
\hline \multicolumn{4}{|l|}{ Educational attainment } \\
\hline \multirow[t]{2}{*}{ No formal degree } & 0.010 & 0.025 & 0.020 \\
\hline & $(0.101)$ & $(0.155)$ & $(0.139)$ \\
\hline \multirow[t]{2}{*}{ Secondary school (9 yrs.) } & 0.299 & 0.339 & 0.413 \\
\hline & $(0.458)$ & $(0.474)$ & $(0.493)$ \\
\hline \multirow[t]{2}{*}{ Secondary school (10 yrs.) } & 0.448 & 0.335 & 0.357 \\
\hline & $(0.497)$ & $(0.472)$ & $(0.480)$ \\
\hline \multirow[t]{2}{*}{ Technical college entrance qualification (11-12 yrs.) } & 0.050 & 0.054 & 0.037 \\
\hline & $(0.218)$ & $(0.227)$ & $(0.188)$ \\
\hline \multirow[t]{2}{*}{ General qualification for university entrance (12-13 yrs.) } & 0.193 & 0.247 & 0.174 \\
\hline & $(0.395)$ & $(0.432)$ & $(0.380)$ \\
\hline \multicolumn{4}{|l|}{ Vocational attainment } \\
\hline \multirow[t]{2}{*}{ No formal degree } & 0.075 & 0.219 & 0.225 \\
\hline & $(0.264)$ & $(0.414)$ & $(0.418)$ \\
\hline \multirow[t]{2}{*}{ Apprenticeship (dual system) } & 0.638 & 0.455 & 0.545 \\
\hline & $(0.481)$ & $(0.498)$ & $(0.499)$ \\
\hline \multirow[t]{2}{*}{ Specialized vocational school } & 0.140 & 0.150 & 0.107 \\
\hline & $(0.347)$ & $(0.357)$ & $(0.309)$ \\
\hline \multirow[t]{2}{*}{ University, technical college } & 0.147 & 0.176 & 0.124 \\
\hline & $(0.354)$ & $(0.381)$ & $(0.330)$ \\
\hline \multicolumn{4}{|l|}{ Previous employment } \\
\hline \multirow[t]{2}{*}{ Net hourly wage (in euros) } & 6.822 & 6.614 & 6.754 \\
\hline & $(3.847)$ & $(3.751)$ & $(3.218)$ \\
\hline \multirow[t]{2}{*}{ Duration (in months) } & 45.233 & 37.096 & 35.216 \\
\hline & $(72.137)$ & $(59.861)$ & $(55.821)$ \\
\hline \# Observations & 6,367 & 773 & 356 \\
\hline
\end{tabular}

Source: IZA Evaluation Dataset, own calculations.

Note: Natives: German-born and German citizen, and parents German-born; first generation: not German-born; second generation: German-born, but not German citizen, or both parents not German-born or age at migration less than or equal to three years. 
Table 2 displays further descriptive statistics for the two groups of migrants in our data. We focus on migrant-specific characteristics to shed more light on the migration background and history of those individuals.

We start by looking at the country of origin of first and second generation migrants. For this purpose, we aggregate the country of origin into three major sending regions: $a$ ) guest worker countries, $b$ ) Central and Eastern European countries, and c) other countries. ${ }^{13}$ The descriptive statistics then basically reflect two major developments in Germany's migration history. For instance, 60 percent of first generation migrants are from Central and Eastern European countries. This substantial share can be explained by the sizeable inflow of ethnic Germans around 1990 and, more generally, by the fall of the Iron Curtain and subsequent East-to-West migration. Similarly, almost two thirds of second generation migrants have a background in guest worker countries. ${ }^{14}$ They are offspring of the guest workers who had migrated to Germany during the post-war economic boom until the early 1970s.

We also see that first generation migrants spent on average already a long time in Germany, and they moved when they were rather young. Average years since migration of first generation migrants exceed 16 years, and the average age at migration is about 19 years. Moreover, more than half of the first generation migrants completed an educational degree abroad and about one in three a vocational degree abroad. These numbers appear plausible as most first generation migrants spent substantial parts of their lives in their country of origin, mostly during childhood and adolescence when schooling takes place.

In contrast, less than one third of second generation migrants have actually moved to Germany. The majority of them were born in Germany. For those not German-born individuals, the average age at migration is of course very low and years since migration high, as we only include individuals who were three years or younger when they migrated. This is in line with the observation that only very few second generation migrants completed a vocational or educational degree abroad (2.5 percent, respectively).

\footnotetext{
${ }^{13}$ Guest worker countries include Turkey, former Yugoslavia, Italy, Spain, and Greece. Central and Eastern European countries include Poland, former USSR, former CSSR, and Romania.

${ }^{14}$ The country of origin of second generation migrants is either $a$ ) their country of birth (if they are not German-born), $b$ ) their country of citizenship (if they do not have German citizenship), or $c$ ) their parents' country of birth or country of citizenship. If the latter is not the same for both parents, we take the father's country (Card et al., 1998; Jonsson, 2007).
} 
Table 2: Descriptive Statistics (Migrants' Characteristics)

\begin{tabular}{|c|c|c|c|c|}
\hline \multirow{2}{*}{ Country of origin (by region) } & \multicolumn{2}{|c|}{ 1st generation } & \multicolumn{2}{|c|}{ 2nd generation } \\
\hline & & & & \\
\hline Guest worker countries ${ }^{a}$ & $N=773$ & $\begin{array}{l}0.193 \\
(0.395)\end{array}$ & $N=356$ & $\begin{array}{l}0.632 \\
(0.483)\end{array}$ \\
\hline Central and Eastern European countries ${ }^{b}$ & $N=773$ & $\begin{array}{l}0.600 \\
(0.490)\end{array}$ & $N=356$ & $\begin{array}{l}0.166 \\
(0.372)\end{array}$ \\
\hline Other countries & $N=773$ & $\begin{array}{l}0.207 \\
(0.405)\end{array}$ & $N=356$ & $\begin{array}{c}0.202 \\
(0.402)\end{array}$ \\
\hline \multicolumn{5}{|l|}{ Time in Germany } \\
\hline Years since migration & $N=773$ & $\begin{array}{c}16.308 \\
(8.490)\end{array}$ & $N=103$ & $\begin{array}{c}29.951 \\
(9.771)\end{array}$ \\
\hline Age at migration & $N=773$ & $\begin{array}{c}18.952 \\
(9.941)\end{array}$ & $N=103$ & $\begin{array}{l}1.544 \\
(1.074)\end{array}$ \\
\hline \multicolumn{5}{|l|}{ Education abroad } \\
\hline Educational degree abroad & $N=773$ & $\begin{array}{l}0.550 \\
(0.498)\end{array}$ & $N=356$ & $\begin{array}{l}0.025 \\
(0.157)\end{array}$ \\
\hline Vocational degree abroad & $N=773$ & $\begin{array}{l}0.354 \\
(0.479)\end{array}$ & $N=356$ & $\begin{array}{l}0.025 \\
(0.157)\end{array}$ \\
\hline
\end{tabular}

Source: IZA Evaluation Dataset, own calculations.

Note: First generation: not German-born; second generation: German-born, but not German citizen, or both parents not German-born or age at migration less than or equal to three years.

${ }^{a}$ Guest worker countries include Turkey, former Yugoslavia, Italy, Spain and Greece.

${ }^{b}$ Central and Eastern European countries include Poland, former USSR, former CSSR and Romania.

In order to measure ethnic identity, we apply the two-dimensional version of the ethnosizer in our empirical analysis (Constant and Zimmermann, 2008; Constant, Gataullina, and Zimmermann, 2009). We argue that the ethnosizer provides an approximation of the different reference groups by measuring the intensity of commitment to the home and the host culture. It is a complex concept, which classifies immigrants into four separate states: $a$ ) assimilation, $b$ ) integration, $c$ ) marginalization, and $d$ ) separation. An assimilated immigrant has a high commitment to the host culture and a weak one to his home culture; being integrated means to be committed to both cultures; marginalization displays a weak dedication to either culture; and separation a strong commitment to the home culture, but not to the host one. See Figure 1 for a visualization of the concept.

These states are formed by combining four essential elements of personal devotion to German culture and society and to the culture of origin: a) language, $b$ ) ethnic self-identification, $c$ ) ethnic interaction, and $d$ ) migration history. ${ }^{15}$

\footnotetext{
${ }^{15}$ Our data does not include exactly the same questions as the GSOEP, which has been used so far to construct the ethnosizer. Therefore, we use a modified version and rely only on four elements; the element "culture" is not included.
} 
Figure 1: The Ethnosizer as a Two-Dimensional Measurement of Ethnic Identity

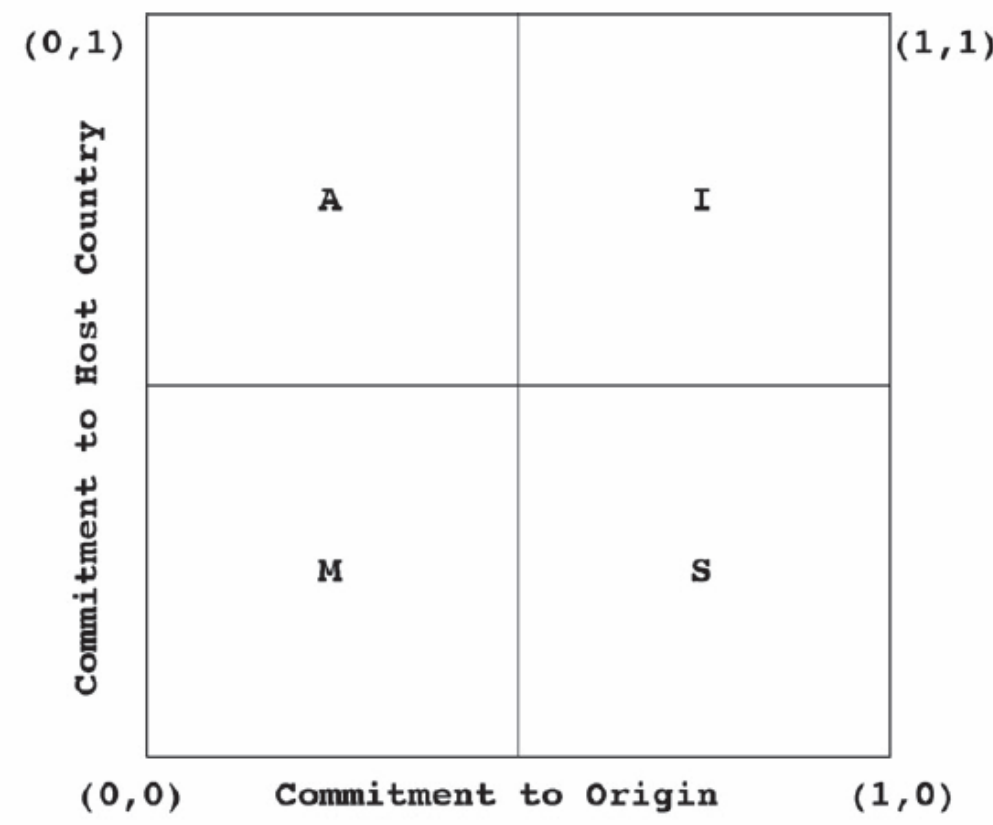

Source: Constant, Gataullina, and Zimmermann (2009).

Note: A: Assimilation; I: Integration; M: Marginalization; S: Separation.

Table 3 displays descriptive statistics of the specific variables we use. For this purpose, we have transformed the different items of the respondents' answers into variables ranging from 0 to 1 . For instance, a higher value corresponds to better German language skills and a more frequent use of a different language than German as family language. Second generation migrants report a better German language proficiency than first generation migrants and a less frequent use of a different language than German as family language. The degree of self-identification with Germany is similar across the two migrant generations in our sample, albeit slightly stronger among second generation migrants. Second generation migrants self-identify to a lower extent with the country of origin, but the difference is small. The use of a different language than German as a means of communication among friends is rather uncommon in the second generation, and more frequent among first generation migrants. Finally, whereas second generation migrants report a lower probability to apply for German citizenship, the reported probability of leaving Germany in the future is very similar across the migrant generations. 
Table 3: Descriptive Statistics (Components of the Ethnosizer)

\begin{tabular}{lcc}
\hline & 1st generation & 2nd generation \\
\hline Language & 0.756 & \\
German language skills & $(0.193)$ & 0.901 \\
Family language & 0.386 & $(0.129)$ \\
& $(0.273)$ & 0.269 \\
& & $(0.254)$ \\
\hline Ethnic self-identification & 0.742 & \\
Self-identification with Germany & $(0.212)$ & 0.763 \\
Self-identification with country of origin & 0.584 & $(0.212)$ \\
& $(0.314)$ & 0.546 \\
& & $0.311)$ \\
\hline Ethnic interaction & 0.328 & \\
Language with friends & $(0.270)$ & 0.195 \\
& & $(0.215)$ \\
\hline Migration history & 0.789 & \\
Intention to apply for German citizenship & $(0.355)$ & 0.709 \\
Center of interest in 5 years (10-15 years) & 0.217 & $(0.396)$ \\
& $(0.241)$ & 0.221 \\
& 773 & $(0.245)$ \\
\hline \# Observations & & 356 \\
\hline
\end{tabular}

Source: IZA Evaluation Dataset, own calculations.

Note: First generation: not German-born; second generation: German-born, but not German citizen, or both parents not German-born or age at migration less than or equal to three years. All variables range between 0 and 1 . A higher value corresponds to better German language skills, a more frequent use of a different language than German as family language, a stronger self-identification with Germany, a stronger self-identification with the country of origin, a more frequent use of another language than German with friends, a higher probability of applying for German citizenship, and a higher probability of leaving Germany.

To construct the four identity states of the ethnosizer for each individual, we proceed as follows: a respondent with a 'very good' or 'good' command of the German language who communicates to his or her family members 'only', 'mainly' or 'partly' in another language is classified as linguistically integrated; a respondent with at least a 'good' command of the German language who communicates to his or her family members 'only' or 'mainly' in German is classified as linguistically assimilated; a respondent with 'fair', 'bad' or 'no' command of the German language who communicates to his or her family members 'only', 'mainly' or 'partly' in another language is classified as linguistically separated; and finally, a respondent with 'fair', 'bad' or 'no' command of the German language who communicates to family members 'only' or 'mainly' in German is classified as linguistically marginalized. Ethnic self-identification as the second element of the ethnosizer is available in our data for both natives and migrants (see Constant, Kahanec, Rinne, and Zimmermann, 2009). 
People who self-identify both strongly with Germany and with the country of origin are considered as integrated; people who self-identify strongly with Germany but to a smaller extent with the country of origin are considered as assimilated; people who self-identify strongly with the country of origin but to a smaller extent with Germany are considered as separated; and, finally, people who self-identify only weakly both with Germany and the country of origin are considered as marginalized. To construct this measure for natives, self-identification with the country of origin is replaced by the attraction of cultures, customs and traditions of other countries. One can therefore think of integrated natives as individuals who show both a strong commitment to Germany but also to foreign countries and foreigners, and thus as people who have a more internationally-oriented perspective. Assimilated, marginalized and separated natives are then classified accordingly. With respect to the other two dimensions of ethnic interaction and migration history, individuals are categorized similarly.

Figure 2 displays the distribution across all four states of the ethnosizer for first and second generation migrants in our sample. The distributions are rather similar: both have the highest score for assimilation, followed by integration and marginalization, and separation ranking last. However, the score for assimilation is higher among the second generation, whereas the scores for all three other dimensions are slightly below those of the first generation. This seems plausible: second generation migrants feel more dedicated to the German culture than first generation migrants. Furthermore, this finding reinforces our hypothesis of changing frames of references from one migrant generation to the next.

There are still comparatively few empirical studies that directly incorporate reservation wages in their analysis. The main reason for this lies in the scarcity of adequate data sets; but our data include self-reported reservation wages, which we can directly incorporate in our analysis. More specifically, respondents were posed the following questions regarding their reservation wage:

a) Now the focus turns to earnings expectations while searching for a job. How high do you expect your net monthly wage to be? How many hours per week would you at least have to work in order to receive this net monthly wage?

b) Would you also be prepared to accept a job offer with a lower net monthly wage? And if so, what is the lowest net monthly wage you would be prepared to accept? How many hours per week would you at least have to work in order to receive this net monthly wage?

The answer to these questions gives us information about the individuals' reservation wage. ${ }^{16}$ Moreover, we calculate the reservation wage ratio (RWR). This ratio is defined as the reservation wage at the time of the interview divided by the previous

\footnotetext{
${ }^{16}$ If both questions are answered, one can interpret response $a$ ) as the conditional expected wage and $b$ ) as the reservation wage (Lancaster and Chesher, 1983).
} 
Figure 2: Two-Dimensional Ethnosizer by Migration Status

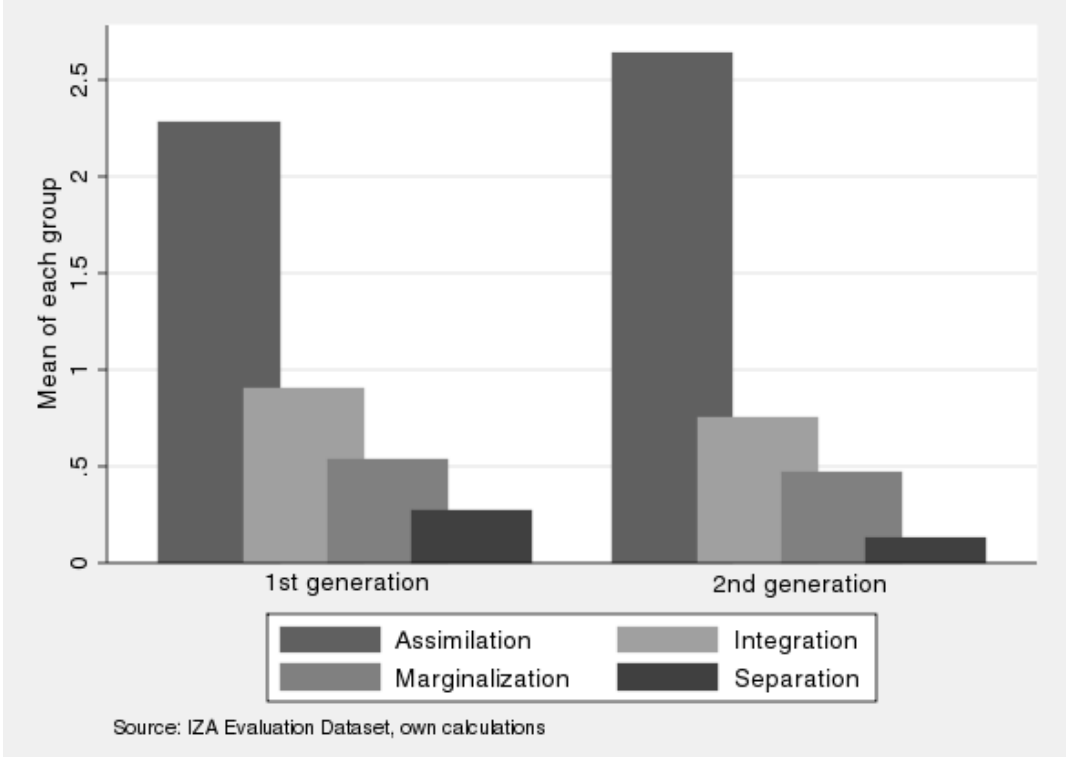

Note: Mean scores for each of the four states of the ethnosizer. First generation: not German-born; second generation: German-born, but not German citizen, or both parents not German-born or age at migration less than or equal to six years.

wage from (self-)employment before entering unemployment.

Table 4 displays the average net hourly reservation wages and reservation wage ratios in our sample. The average reservation wage for the entire sample is $€ 7.05$, which corresponds to an 11 percent increase compared to the previous wage. Regarding the three subgroups, it is apparent that the natives' reservation wage lies slightly below the total average at $€ 7.03$. First and second generation migrants both have a reservation wage exceeding the total average. The second generation has the highest with $€ 7.42$ per hour. The reservation wage ratios are rather similar across the three groups. We further differentiate individuals according to the four regimes of ethnic self-identification. It becomes apparent that integrated individuals have the highest reservation wages, where the ones for natives and second generation migrants are particularly high with $€ 7.50$. Integrated first generation migrants have a reservation wage of $€ 7.27$.

When comparing the reservation wages to previous wage levels, assimilated natives and assimilated second generation migrants have relatively moderate wage aspirations: reservation wages exceed previous wages by 8 and 5 percent, respectively. Among first generation migrants, integrated individuals have the lowest reservation wage ratio, translating into to a 7 percent increase compared to the previous wage. On the other hand, the relative wage aspirations of separated natives and, in particular, of separated second generation migrants are high. The latter aspire a 32 percent increase compared to the previous wage. The overall picture thus sug- 
gests that reservation wages are related to previous wage levels, and individuals seem to regard those as a reference for future wages. However, there is a considerable degree of variation across individuals of different migration status, and also across the four regimes of ethnic self-identification.

When looking separately at West and East Germans as well as male and female individuals, two important observations become apparent: a) men generally have higher reservation wages than women, and $b$ ) individuals living in West Germany generally have higher reservation wages than East Germans. ${ }^{17}$ Hence, men in West Germany have the highest reservation wages irrespective of their migration status. Possible reasons for these findings are that wage levels in West Germany and for men are on average higher than in East Germany and for women. Natives and second generation migrants have the highest reservation wages in West Germany, whereas in East Germany first generation migrants have rather high reservation wages. Moreover, the reservation wage ratios in terms of monthly earnings are lower than those calculated with hourly wages. This finding suggests that hourly reservation wages exceeding previous wages are not necessarily resulting from higher monthly earnings aspirations. Individuals seem to aspire similar earnings as they previously had, but would like to work less hours for the same amount of money.

Table 4: Reservation Wage (RW) and Reservation Wage Ratio (RWR) by Migration Status and Ethnic Self-Identification

\begin{tabular}{|c|c|c|c|c|c|c|c|c|}
\hline & \multicolumn{2}{|c|}{$\begin{array}{l}\text { Natives and } \\
\text { Migrants }\end{array}$} & \multicolumn{2}{|c|}{ Natives } & \multicolumn{2}{|c|}{$\begin{array}{l}\text { Migrants } \\
\text { (1st gen.) }\end{array}$} & \multicolumn{2}{|c|}{$\begin{array}{l}\text { Migrants } \\
\text { (2nd gen.) }\end{array}$} \\
\hline & RW & RWR & RW & RWR & RW & RWR & RW & RWR \\
\hline Total & 7.05 & 1.11 & 7.03 & 1.10 & 7.11 & 1.12 & 7.42 & 1.12 \\
\hline Assimilation & 7.03 & 1.08 & 7.01 & 1.08 & 7.03 & 1.14 & 7.35 & 1.05 \\
\hline Integration & 7.46 & 1.12 & 7.50 & 1.12 & 7.27 & 1.07 & 7.50 & 1.16 \\
\hline Marginalization & 6.68 & 1.12 & 6.66 & 1.12 & 6.87 & 1.16 & 7.50 & 1.14 \\
\hline Separation & 6.93 & 1.19 & 6.91 & 1.19 & 6.99 & 1.15 & 7.15 & 1.32 \\
\hline \# Observations & 7,496 & 7,113 & 6,367 & 6,073 & 773 & 704 & 356 & 336 \\
\hline
\end{tabular}

Source: IZA Evaluation Dataset, own calculations.

Note: Net hourly reservation wage (RW, in euros). The reservation wage ratio (RWR) is defined as the reservation wage divided by the previous hourly wage from (self-)employment before entering unemployment.

${ }^{17}$ See Tables A1 and A2 (Appendix) for the detailed numbers. 


\section{Results}

The raw differences in mean reservation wages may be driven by differences in characteristics between natives, first and second generation migrants. We therefore control in a next step for such characteristics. Furthermore, we perform a decomposition analysis of the reservation wage gaps between the three groups considered. By doing so, we are able to shed more light on the underlying mechanisms driving our results.

\subsection{OLS Regressions}

To control for differences in characteristics between natives, first and second generation migrants, we run OLS regressions of the individuals' reservation wage and compare the results with the unconditional gaps. The regressions include sociodemographic characteristics, household characteristics, educational and vocational attainment, unemployment benefits, previous employment and other explanatory variables. We also control for the individuals' locus of control by including the full index as defined in Caliendo et al. (2010). ${ }^{18}$ Finally, we include measures of ethnic identity as described above.

Table 5 displays the OLS regression results for the entire sample (first three columns) as well as for the sub-sample of migrants (last five columns). For the entire sample, we find unconditional reservation wage gaps of 1.6 percent for first generation migrants and 5.9 percent for second generation migrants when compared to natives, see column (1). In other words, without controlling for differences in characteristics both migrant generations have higher reservation wages than natives. Note that only the difference between natives and second generation migrants is significantly different from zero. When including control variables other than ethnic identity, these gaps decrease, see column (2). In the case of first generation migrants, the gap even becomes negative. However, the positive difference in reservation wages between second generation migrants and natives persists, but it is not significant anymore. Results remain virtually the same when additionally including ethnic self-identification as a further explanatory variable, see column (3).

When focusing on migrants only, the raw reservation wage gap amounts to 4.3 percent. The unconditional reservation wage of second generation migrants thus exceeds the one of first generation migrants, see column (4). However, when including a number of additional control variables, this gap increases, see columns (5)-(7). Second generation migrants have conditional reservation wages which are 5.1 percent higher than those of the first generation. Including the ethnosizer or ethnic

\footnotetext{
${ }^{18}$ Caliendo et al. (2010) show that individuals with a more external locus of control have significantly lower reservation wages. Our results (not reported below) confirm this finding.
} 
self-identification leaves our estimates virtually unchanged. But when we also add interaction terms which interact the second generation dummy with the four states of the ethnosizer, the reservation wage gap decreases to 3.7 percent and becomes insignificantly different from zero, see column (8). Therefore, it seems that the ethnosizer is able to explain at least part of the difference in reservation wages between first and second generation migrants-once interactions are included. Ethnic self-identification alone does not have this explanatory power.

Altogether, the results of the OLS regressions confirm our working hypothesis: second generation migrants indeed have higher reservation wages than first generation migrants. We also find evidence that changing frames of reference may be related to this finding, as far as one can indeed view the ethnosizer as a proper approximation of reference groups. Our results show that controlling for ethnic identity, i.e., including the ethnosizer and interaction terms, reduces the reservation wage gap between the two migrant generations.

\subsection{Decomposition}

Our previous results indicate a reservation wage gap between natives and migrantsespecially between natives and second generation migrants-as well as between first and second generation migrants. In order to shed more light on the underlying mechanisms driving these findings, we perform a Blinder-Oaxaca decomposition (Blinder, 1973; Oaxaca, 1973). ${ }^{19}$ Its basic idea is to divide the wage gap between two groups into an explained part resulting from different characteristics such as education and work experience (endowments) and an unexplained part resulting from differences in returns to characteristics (coefficients). We additionally include an interaction term which captures the fact that differences in endowments and characteristics exist simultaneously between the two groups, see Jann (2008). Since we analyze differences in reservation wages and not in actual wages, the unexplained part represents differences in self-evaluations of the individuals, given the same characteristics, and not different rates of return in the market.

Table 6 displays the results of the decomposition. We start by comparing first and second generation migrants. The mean outcome difference of 4.3 percent equals the coefficient of the dummy variable for the second generation in the baseline regression of migrants without any controls. We find a small, but positive endowment effect. This seems to be mainly related to the different age distribution of the second generation in comparison to the first generation. On the other hand, the significantly positive coefficient effect, which is even larger than the mean outcome difference, suggests a higher self-evaluation of second generation migrants when compared to

\footnotetext{
${ }^{19}$ See, e.g., Thomsen et al. (2008) for a study using a similar methodology to analyze wage gaps between migrants and natives in Germany.
} 


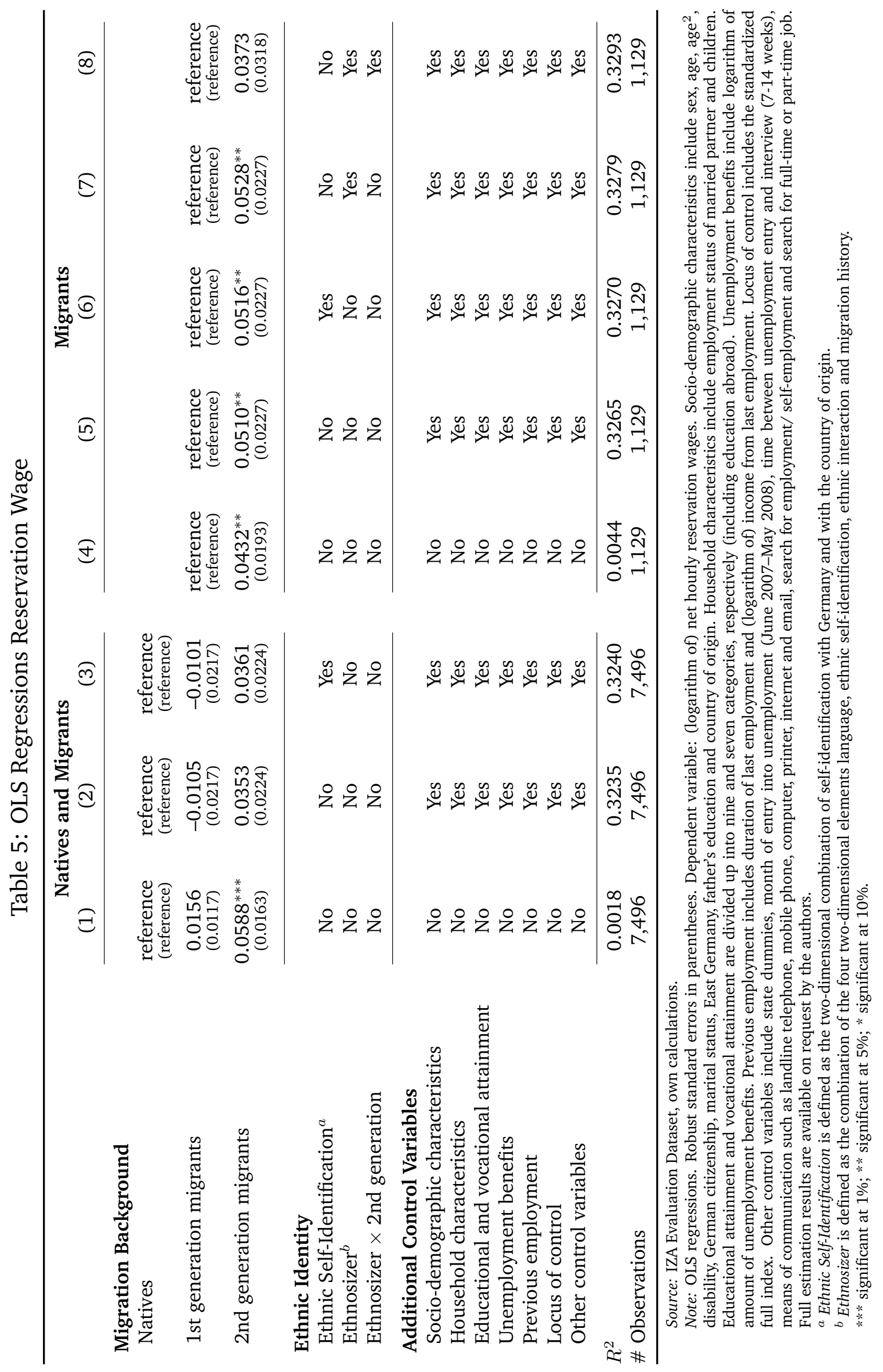


first generation migrants. This is in line with our working hypothesis. More specifically, it appears that especially the returns to education are higher evaluated by the second generation. ${ }^{20}$ The interaction effect is very small and negative.

The second column displays the results of the decomposition analysis for first generation migrants and natives. First generation migrants have a reservation wage which is 1.5 percent higher than that of natives, without controlling for differences in characteristics. The endowment effect is positive, but very small and insignificant. The coefficient effect is negative and also insignificantly different from zero. The interaction effect accounts for the largest part of the gap and is positive, which implies that the self-evaluation of first generation migrants tends to be higher for those characteristics for which they have higher means (e.g., education). All effects are insignificantly different from zero, and also the difference itself.

The third column shows the results of the decomposition analysis for second generation migrants and natives. We observe significantly higher reservation wages of second generation migrants (5.8 percent). This difference is mostly explained by the interaction effect, suggesting that second generation migrants overestimate their expected returns for characteristics of which they have higher means. For instance, this applies for characteristics reflecting the household composition. Both, the endowment and coefficient effect are virtually zero.

Table 6: Blinder-Oaxaca Decomposition

\begin{tabular}{|c|c|c|c|}
\hline & $\begin{array}{l}\text { 2nd generation vs. } \\
\text { 1st generation }\end{array}$ & $\begin{array}{l}\text { 1st generation } \\
\text { vs. natives }\end{array}$ & $\begin{array}{l}\text { 2nd generation } \\
\text { vs. natives }\end{array}$ \\
\hline Difference & $0.0432^{* *}$ & 0.0156 & $0.0588^{* * *}$ \\
\hline Endowments & -0.0260 & 0.0036 & 0.0031 \\
\hline Coefficients & 0.0617 & -0.0102 & -0.0060 \\
\hline Interactions & -0.0075 & 0.0223 & 0.0616 \\
\hline \# Obs. (group 1) & 356 & 773 & 356 \\
\hline \# Obs. (group 2) & 773 & 6,367 & 6,367 \\
\hline
\end{tabular}

Source: IZA Evaluation Dataset, own calculations.

Note: Dependent variable: (logarithm of) net hourly reservation wages. Additional control variables include sex, age, $\mathrm{age}^{2}$, disability, German citizenship, marital status, employment status of married partner, children, East Germany, country of origin, educational attainment, vocational attainment, father's education, duration of last employment, logarithm of amount of unemployment benefits, state dummies, cohort dummies, time lag dummies, (logarithm of) income from last employment, means of communication, locus of control, search for employment/ self-employment and search for full-time or part-time job. The ethnosizer and ethnic self-identification are also included (if applicable). Full estimation results are available on request by the authors.

$* * *$ significant at $1 \%$; ** significant at $5 \% ; *$ significant at $10 \%$.

\footnotetext{
${ }^{20}$ The results of a more detailed decomposition analysis are available from the authors upon request.
} 
Altogether, we find that there are differences between migrant generations regarding their reservation wages, but importantly also with respect to their selfevaluation-and therefore very likely with respect to their reference groups. In comparison to first generation migrants, especially the returns to education are higher evaluated by second generation migrants.

\section{Sensitivity Analysis}

In order to check the robustness of our results, we conduct a twofold sensitivity analysis varying the definitions of first and second generation migrants, respectively. In the first part, we split the-potentially heterogeneous-group of first generation into two subgroups; and the second robustness check uses a different threshold for age at migration when defining second generation migrants.

\subsection{Heterogeneity of First Generation}

One may argue that there exists some heterogeneity within the group of first generation migrants. For instance, the years since those individuals have migrated and the age at which migration took place vary considerably. The assumption for all first generation migrants to have their reference group still in their country of origin may be questionable when they have lived in Germany for a very long time already or when they have arrived at a young age. Therefore, we perform a sensitivity analysis in which we split the first generation into two groups. One subgroup of first generation migrants consists of individuals who have been in Germany for at least 15 years and were 13 years or younger when they arrived (henceforth referred to as 'established first generation migrants'). Since those individuals have been in Germany already for a relatively long time and arrived when they were rather young, we expect this subgroup to be closer to the second generation. It may well be the case that their reference group has shifted towards Germany. The second subgroup of first generation migrants consists of the remaining individuals who moved to Germany, but who either have been in Germany for less than 15 years or who were at least 14 years old when they arrived ('recent first generation migrants').

Table A3 (Appendix) displays the results. Without adding further controls, second generation migrants and established first generation migrants both have a significantly higher reservation wage of about 4 percent than natives. Recent first generation migrants have a slightly higher reservation wage than natives, but not significantly, see column (1). When we add further controls and ethnic self-identification, results displayed in column (2) and (3), we see that recent first generation migrants have significantly lower reservation wages than natives, and the second generation 
still significantly higher. Established first generation migrants are in between the two: the coefficients are positive, but insignificant. This seems plausible since the recent first generation migrants are supposed to have their reference group still in the country of origin-leading to lower reservation wages than natives. In contrast, established first generation migrants are expected to be closer to the second generation and supposedly adapted a more German-oriented perspective.

Columns (4) to (8) display the results for migrants only. Second generation migrants and established first generation migrants both have a higher reservation wage than recent first generation migrants. This confirms our hypothesis that reservation wages increase between generations, but also with the time spent in Germany.

\subsection{Definition Second Generation: Age at Migration}

In the second part of the sensitivity analysis, we vary the definition of the second generation. So far, second generation migrants include $a$ ) individuals who are Germanborn, but do not have German citizenship or both parents are not German-born, and b) individuals who are not German-born, but have moved to Germany when they were at most three years old. We now use a different threshold for age at migration. More specifically, we now also include individuals who moved to Germany when they were at most six years old. This is the typical school entrance age in Germany, and thus those individuals have gone through the entire school education (but not pre-school education) in Germany. This change affects 84 individuals compared to our baseline definition: the group of second generation migrants increases by this number-at the cost of an analogous decrease in the number of first generation migrants.

See Table A4 (Appendix) for the results. In columns (1) to (3), we see that the reservation wage gap between second generation migrants and natives does not change compared to previous results: it is still positive and significant. On the other hand, first generation migrants have a more pronounced negative gap compared to natives, which seems plausible since first generation migrants now consist of a more narrowly defined group which is supposedly still more strongly attached to their country of origin. When focussing on migrants, the reservation wage gap between the two generations becomes apparent again controlling for differences in characteristics. Results are displayed in columns (4) to (8). The dummy for second generation migrants becomes positive and significantly different from zero when including further control variables. It shows that changing the definition of the second generation does not affect the evidence on our hypothesis of increasing reservation wages. 


\section{Conclusions}

This paper provides empirical evidence on the reservation wages of first and second generation migrants in Germany (and also in comparison to those of native job seekers). Two extensions of the basic model of job search provide theoretical justifications for the hypothesis of increasing reservation wages from one migrant generation to the next: $a$ ) an unknown wage offer distribution, and $b$ ) reference standards. In both cases, changing frames of reference are identified as a channel through which the phenomenon of increasing reservation wages may arise. For instance, reservation wages become a function of the job seekers' beliefs if the assumption of a known wage offer distribution is relaxed in the basic job search model. We furthermore argue that such beliefs are formed via reference groups, and that these reference groups shift over migrant generations. While first generation migrants may still be relatively strongly attached to their country of origin, beliefs of second generation migrants are supposedly more strongly based on German experiences.

Our empirical findings confirm the hypothesis of increasing reservation wages from one migrant generation to the next. We find an unconditional reservation wage gap of 4.3 percent between first and second generation migrants, i.e., the reservation wages of second generation migrants indeed exceed those of the first generation. This gap increases to about 5.1 percent once differences in characteristics are taken into account. Moreover, we present evidence that changing frames of reference explain at least part of this gap: if we additionally control for reference groups via the ethnosizer, the reservation wage gap decreases to 3.7 percent and becomes statistically insignificant. A Blinder-Oaxaca decomposition of the reservation wage gap reveals further insights. It becomes apparent that the coefficient effect drives the unconditional reservation wage gap between the two migrant generations. Our results thus suggest that second generation migrants self-evaluate the returns to characteristics higher than first generation migrants, and especially with respect to the expected returns to education.

This paper provides the basis for a related analysis: in the process of job search, the intensity as well as the methods of search may also vary between migrant generations. Whereas this paper treats those dimensions basically as given, there is empirical evidence for differences between natives and migrants in this regard (see, e.g., Frijters et al., 2005). Therefore, an extension that differentiates between migrant generations in those dimensions appears obvious. 


\section{References}

Algan, Y., C. Dustmann, A. Glitz, and A. Manning (2010). The Economic Situation of First- and Second-Generation Immigrants in France, Germany, and the United Kingdom. The Economic Journal 120(542), 4-30.

Bikhchandani, S. and S. Sharma (1996). Optimal Search With Learning. Journal of Economic Dynamics and Control 20(1-3), 333-359.

Blackaby, D., D. Leslie, P. Murphy, and N. O'Leary (2005). Born in Britain: How are Native Ethnic Minorities Faring in the British Labour Market? Economics Letters 88(3), 370-375.

Blinder, A. S. (1973). Wage Discrimination: Reduced Form and Structural Estimates. Journal of Human Resources 8(4), 436-455.

Bonin, H., T. Dohmen, A. Falk, D. Huffman, and U. Sunde (2007). Cross-sectional Earnings Risk and Occupational Sorting: The Role of Risk Attitudes. Labour Economics 14(6), 926-937.

Borghans, L., A. L. Duckworth, J. J. Heckman, and B. ter Weel (2008). The Economics and Psychology of Personality Traits. Journal of Human Resources 43(4), 972-1059.

Borjas, G. J. (1992). Ethnic Capital and Intergenerational Mobility. Quarterly Journal of Economics 107(1), 123-150.

Burdett, K. and T. Vishwanath (1988). Declining Reservation Wages and Learning. The Review of Economic Studies 55(4), 655-665.

Cahuc, P. and A. Zylberberg (2004). Labor Economics. MIT Press.

Caliendo, M., D. A. Cobb-Clark, and A. Uhlendorff (2010). Locus of Control and Job Search Strategies. IZA Discussion Paper 4750, Institute for the Study of Labor (IZA), Bonn.

Caliendo, M., A. Falk, L. C. Kaiser, H. Schneider, A. Uhlendorff, G. J. van den Berg, and K. F. Zimmermann (2009). The IZA Evaluation Data Set - The First Wave. Working Paper, Institute for the Study of Labor (IZA), Bonn.

Card, D., J. DiNardo, and E. Estes (1998). The More Things Change: Immigrants and the Children of Immigrants in the 1940s, the 1970s and the 1990s. NBER Working Paper 6519, National Bureau of Economic Research, Inc, Cambridge, MA.

Constant, A. F., L. Gataullina, and K. F. Zimmermann (2009). Ethnosizing Immigrants. Journal of Economic Behavior \& Organization 69(3), 274-287.

Constant, A. F., M. Kahanec, U. Rinne, and K. F. Zimmermann (2009). Ethnicity, Job Search and Labor Market Reintegration of the Unemployed. IZA Discussion Paper 4660, Institute for the Study of Labor (IZA), Bonn.

Constant, A. F. and K. F. Zimmermann (2005). Legal Status at Entry, Economic Performance, and Selfemployment Proclivity: A Bi-national Study of Immigrants. IZA Discussion Paper 1910, Institute for the Study of Labor (IZA), Bonn.

Constant, A. F. and K. F. Zimmermann (2008). Measuring Ethnic Identity and Its Impact on Economic Behavior. Journal of the European Economic Association 6(2-3), 424-433.

Constant, A. F. and K. F. Zimmermann (2009). Work and Money: Payoffs by Ethnic Identity and Gender. Research in Labor Economics 29, 3-30.

Dubra, J. (2004). Optimism and Overconfidence in Search. Review of Economic Dynamics 7(1), 198-218.

Falk, A. and M. Knell (2004). Choosing the Joneses: On the Endogeneity of Reference Standards. Scandinavian Journal of Economics 106(3), 417-435.

Franz, W. (1980). The Reservation Wage of Unemployed Persons in the Federal Republic of Germany: Theory and Empirical Tests. NBER Working Paper 578, National Bureau of Economic Research, Inc, Cambridge, MA.

Franzen, A. and D. Hangartner (2006). Social Networks and Labour Market Outcomes: The NonMonetary Benefits of Social Capital. European Sociological Review 22(4), 353-368.

Frijters, P., M. A. Shields, and S. Wheatley Price (2005). Job Search Methods and Their Success: A Comparison of Immigrants and Natives in the UK. The Economic Journal 115(507), F359-F376.

Gang, I. N. and K. F. Zimmermann (2000). Is Child like Parent? Educational Attainment and Ethnic Origin. Journal of Human Resources 35(3), $550-569$.

Granovetter, M. (1995). Getting a Job: A Study of Contacts and Careers (2nd ed.). London and Chicago: University of Chicago Press. 
Heath, A. F. and Y. Li (2008). Period, Life-Cycle and Generational Effects on Ethnic Minorities. In F. Kalter (Ed.), Migration und Integration, Kölner Zeitschrift für Soziologie und Sozialpsychologie, Sonderheft 48, pp. 277-306.

Heath, A. F., C. Rothon, and E. Kilpi (2008). The Second Generation in Western Europe: Education, Unemployment, and Occupational Attainment. Annual Review of Sociology 34(1), 211-35.

Heckman, J. J., J. Stixrud, and S. Urzua (2006). The Effects of Cognitive and Noncognitive Abilities on Labor Market Outcomes and Social Behavior. Journal of Labor Economics 24(3), 411-482.

Jann, B. (2008). The Blinder-Oaxaca Decomposition for Linear Regression Models. Stata Journal 8(4), 453-479.

Jonsson, J. O. (2007). The Farther They Come, the Harder They Fall? First- and Second-Generation immigrants in the Swedish Labour Market. In A. F. Heath and S. Y. Cheung (Eds.), Unequal Chances: Ethnic Minorities in Western Labour Markets, pp. 451-505.

Kahanec, M. and A. Zaiceva (2009). Labor Market Outcomes of Immigrants and Non-citizens in the EU: An East-West Comparison. International Journal of Manpower 30(1/2), 97-115.

Kalter, F. and N. Granato (2007). Educational Hurdles on the Way to Structural Assimilation in Germany. In A. F. Heath and S. Y. Cheung (Eds.), Unequal Chances: Ethnic Minorities in Western Labour Markets, pp. 271-319.

Kogan, I. (2007). Continuing Ethnic Segmentation in Austria. In A. F. Heath and S. Y. Cheung (Eds.), Unequal Chances: Ethnic Minorities in Western Labour Markets, pp. 103-141.

Kohn, M. and S. Shavell (1974). The Theory of Search. Journal of Economic Theory 9(2), 93-123.

Kriechel, B. and G. A. Pfann (2006). Learning to Update Your Reservation Wage While Looking for a New Job. Portuguese Economic Journal 5(2), 135-148.

Lancaster, T. and A. Chesher (1983). An Econometric Analysis of Reservation Wages. Econometrica 51(6), 1661-1676.

McCall, J. (1970). Economics of Information and Job Search. Quarterly Journal of Economics 84(1), 113-126.

Mortensen, D. T. (1970). Job Search, the Duration of Unemployment, and the Philipps Curve. American Economic Review 60(5), 847-862.

Oaxaca, R. (1973). Male-Female Wage Differentials in Urban Labor Markets. International Economic Review 14(3), 693-709.

Phalet, K. (2007). Down and Out: The Children of Migrant Workers in the Belgian Labour Market. In A. F. Heath and S. Y. Cheung (Eds.), Unequal Chances: Ethnic Minorities in Western Labour Markets, pp. $143-180$.

Portes, A. and M. Zhou (1993). The New Second Generation: Segmented Assimilation and its Variants. The ANNALS of the American Academy of Political and Social Science 530(1), 74-96.

Rühl, S. (2009). Grunddaten der Zuwanderungsbevölkerung in Deutschland. Working Paper 27, Bundesamt für Migration und Flüchtlinge, Nürnberg.

Riphahn, R. T. (2003). Cohort Effects in the Educational Attainment of Second Generation Immigrants in Germany: An Analysis of Census Data. Journal of Population Economics 16(4), 711-737.

Rothschild, M. (1974). Searching for the Lowest Price When the Distribution of Prices Is Unknown. Journal of Political Economy 82(4), 689-711.

Silberman, R. and I. Fournier (2007). Is French Society Truly Assimilative? Immigrant Parents and Offspring on the French Labour Market. In A. F. Heath and S. Y. Cheung (Eds.), Unequal Chances: Ethnic Minorities in Western Labour Markets, pp. 221-269.

Åslund, O., A. Böhlmark, and O. N. Skans (2009). Age at Migration and Social Integration. IZA Discussion Paper 4263, Institute for the Study of Labor (IZA), Bonn.

Stark, O. and J. Taylor (1991). Migration Incentives, Migration Types: The Role of Relative Deprivation. The Economic Journal 101 (408), 1163-1178.

Thomsen, S. L., J. Gernandt, and A. Aldashev (2008). The Immigrant Wage Gap in Germany. ZEW Discussion Paper 08-089, Center for European Economic Research (ZEW), Mannheim.

Uhlendorff, A. and K. F. Zimmermann (2006). Unemployment Dynamics among Migrants and Natives. IZA Discussion Paper 2299, Institute for the Study of Labor (IZA), Bonn.

Zimmermann, K. F., A. F. Constant, and L. Gataullina (2009). Naturalization Proclivities, Ethnicity and Integration. International Journal of Manpower 30(1/2), 70-82. 


\section{Appendix}

\section{A1 Job Search and Reference Standards}

We incorporate reference standards into the basic model of job search by assuming that the absolute wage $w_{i}$ as well as the reference standard $\left(w_{i}-r_{i}\right)$ contribute in a linear way to the utility of an employed individual $i$ (Falk and Knell, 2004). The discounted expected utility $V_{e}$ of an employed person can then be expressed as:

$$
V_{e}\left(w_{i}\right)=\frac{1}{1+d}\left((1-\theta) w_{i}+\theta\left(w_{i}-r_{i}\right)+(1-q) V_{e}\left(w_{i}\right)+q V_{u}\right),
$$

where the discount rate is equal to $d$, the parameter $\theta$ determines the extent to which comparisons play a role, jobs are separated exogenously with probability $q$ per period, and $V_{u}$ is the discounted expected utility of an unemployed person. Rearranging the terms of equation (A1), we arrive at:

$$
d V_{e}\left(w_{i}\right)=(1-\theta) w_{i}+\theta\left(w_{i}-r_{i}\right)+q\left(V_{u}-V_{e}\left(w_{i}\right)\right) .
$$

If an unemployed individual receives a job offer, he or she accepts the offer if $V_{e}\left(w_{i}\right)>V_{u}$, and thus if:

$$
V_{e}\left(w_{i}\right)-V_{u}=\frac{\left((1-\theta) w_{i}+\theta\left(w_{i}-r_{i}\right)\right)-d V_{u}}{d+q}>0 .
$$

The reservation wage, i.e., the crucial wage above which an individual $i$ is willing to accept job offers, is defined as a threshold value $\xi_{i}$. Accepting a job offer with wage $\xi_{i}$ yields the same utility that the unemployed individual gets by remaining unemployed:

$$
(1-\theta) \xi_{i}+\theta\left(\xi_{i}-r_{i}\right)=d V_{u} .
$$

Note that the reference standard enters this expression. Alternatively, we can express the reservation wage as:

$$
\xi_{i}=d V_{u}+\theta r_{i} .
$$

The discounted expected income of an unemployed individual does not change compared to the basic model of job search (cf. Cahuc and Zylberberg, 2004):

$$
d V_{u}=z+\lambda \int_{\xi_{i}}^{\infty}\left(V_{e}\left(w_{i}\right)-V_{u}\right) \mathrm{d} H\left(w_{i}\right),
$$

where $z$ are the net benefits when unemployed (i.e., the difference between unemployment benefits $b$ and search costs $c), H(w)$ is the wage offer distribution and $\lambda$ the job offer arrival rate.

Hence, inserting equations (A3) and (A5) into the latter expression yields:

$$
\xi_{i}=z+\frac{\lambda}{d+q} \int_{\xi_{i}}^{\infty}\left(w_{i}-\xi_{i}\right) \mathrm{d} H\left(w_{i}\right)+\theta r_{i} .
$$




\section{A2 Additional Tables}

Table A1: Reservation Wage (RW) and Reservation Wage Ratio (RWR) by Migration Status, Ethnic Self-Identification, Region and Gender

\begin{tabular}{|c|c|c|c|c|c|c|c|c|}
\hline & \multicolumn{2}{|c|}{$\begin{array}{c}\text { Natives and } \\
\text { Migrants }\end{array}$} & \multicolumn{2}{|c|}{ Natives } & \multicolumn{2}{|c|}{$\begin{array}{l}\text { Migrants } \\
\text { (1st gen.) }\end{array}$} & \multicolumn{2}{|c|}{$\begin{array}{l}\text { Migrants } \\
\text { (2nd gen.) }\end{array}$} \\
\hline & RW & RWR & RW & RWR & RW & RWR & RW & RWR \\
\hline Men West & 7.85 & 1.12 & 7.88 & 1.11 & 7.65 & 1.17 & 7.93 & 1.11 \\
\hline Women West & 6.98 & 1.08 & 7.02 & 1.08 & 6.67 & 1.07 & 7.10 & 1.12 \\
\hline Men East & 6.57 & 1.13 & 6.55 & 1.13 & 6.89 & 1.11 & 6.92 & 1.16 \\
\hline Women East & 5.91 & 1.12 & 5.89 & 1.12 & 6.57 & 1.11 & 5.94 & 1.25 \\
\hline \# Observations & 7,496 & 7,113 & 6,367 & 6,073 & 773 & 704 & 356 & 336 \\
\hline
\end{tabular}

Source: IZA Evaluation Dataset, own calculations.

Note: Net hourly reservation wage (RW, in euros). The reservation wage ratio (RWR) is defined as the reservation wage divided by the previous hourly wage from (self-)employment before entering unemployment.

Table A2: Reservation Wage (RW) and Reservation Wage Ratio (RWR) by Migration Status and Ethnic Self-Identification-Earnings

\begin{tabular}{|c|c|c|c|c|c|c|c|c|}
\hline & \multicolumn{2}{|c|}{$\begin{array}{c}\text { Natives and } \\
\text { Migrants }\end{array}$} & \multicolumn{2}{|c|}{ Natives } & \multicolumn{2}{|c|}{$\begin{array}{l}\text { Migrants } \\
\text { (1st gen.) }\end{array}$} & \multicolumn{2}{|c|}{$\begin{array}{l}\text { Migrants } \\
\text { (2nd gen.) }\end{array}$} \\
\hline & RW & RWR & RW & RWR & RW & RWR & RW & RWR \\
\hline Total & 1108.83 & 1.06 & 1105.73 & 1.06 & 1108.83 & 1.09 & 1164.30 & 1.07 \\
\hline Assimilation & 1102.74 & 1.03 & 1102.85 & 1.03 & 1062.12 & 1.09 & 1181.05 & 1.02 \\
\hline Integration & 1167.05 & 1.08 & 1175.82 & 1.08 & 1140.46 & 1.04 & 1141.06 & 1.09 \\
\hline Marginalization & 1063.82 & 1.08 & 1059.18 & 1.08 & 1095.98 & 1.12 & 1198.65 & 1.04 \\
\hline Separation & 1086.04 & 1.11 & 1070.21 & 1.08 & 1157.79 & 1.26 & 1158.00 & 1.26 \\
\hline \# Observations & 7,496 & 7,113 & 6,367 & 6,073 & 773 & 704 & 356 & 336 \\
\hline
\end{tabular}

Source: IZA Evaluation Dataset, own calculations.

Note: Net monthly reservation wage (RW, in euros). The reservation wage ratio (RWR) is defined as the reservation wage divided by the previous wage from (self-)employment before entering unemployment. 


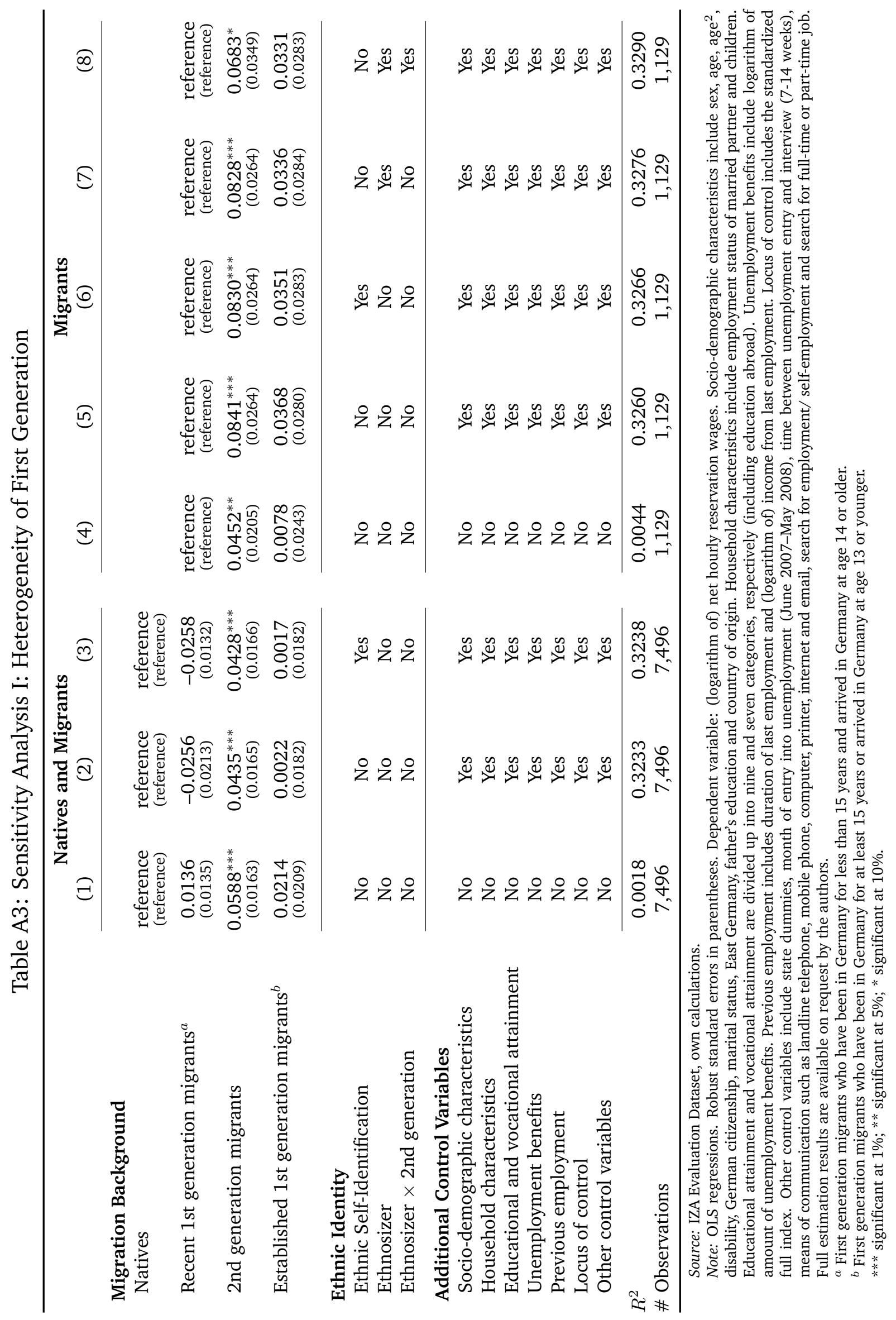




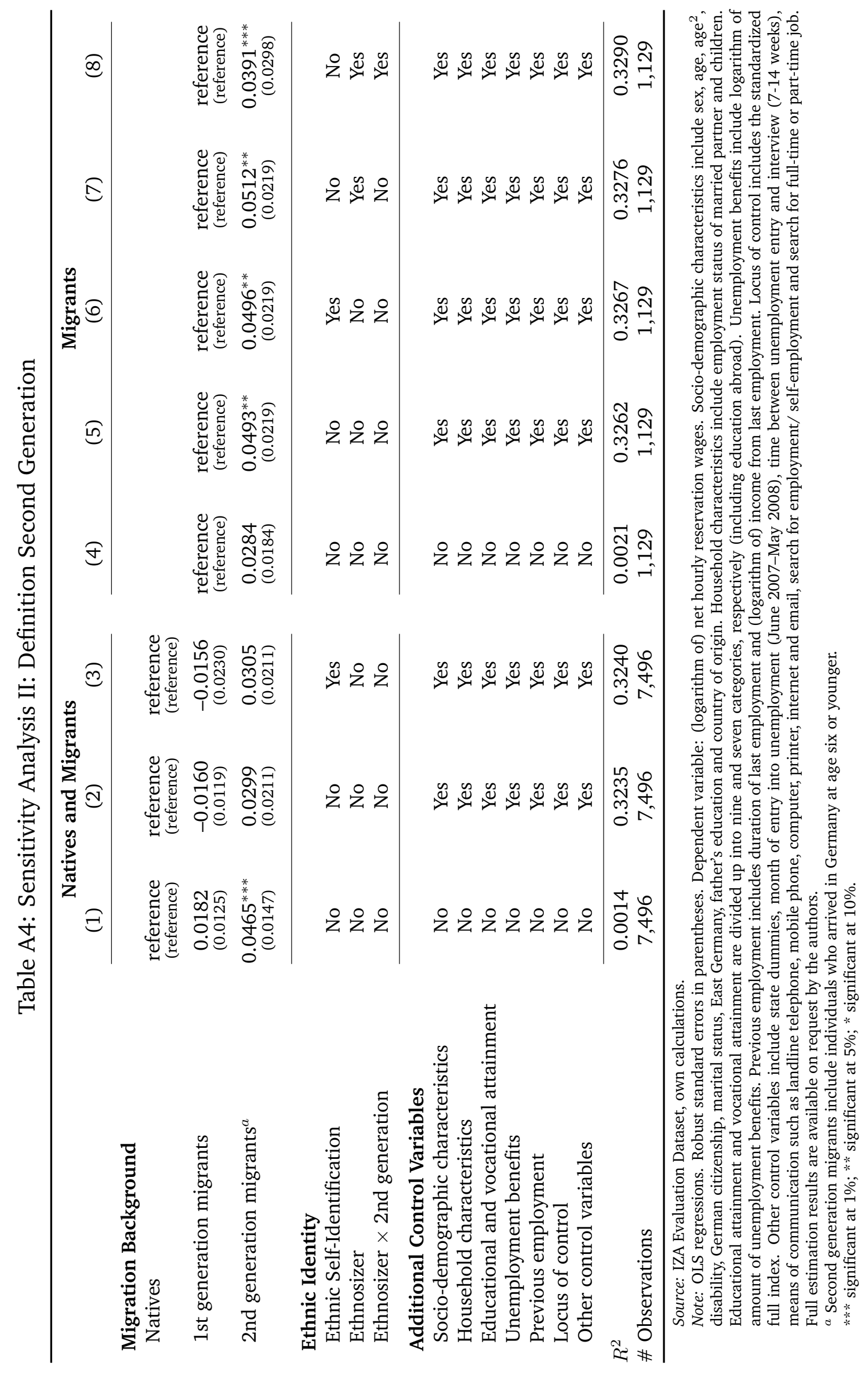

